\title{
A Study on the Food Product Commercials in Television with Reference to Humour Appeal
}

Shobana Sankaran*

Masters in Electronic Media, CEG, Anna University, Tamil Nadu, India

\begin{abstract}
Humour plays a vital role in television commercials. Humour appeals used in food product commercials has its own elements. The following study examines the elements present in food product commercials based on humour appeal. The study also determines the end users perception of humour based food product television commercials and the recall factor in humour based food product commercials.
\end{abstract}

Keywords: Television; Advertisement; Food product; commercial; Violence

\section{Introduction}

The word advertising is derived from the Latin word "Advertere". Advertising has acquired a great importance in modern India by advancing the creativity and technology in this fast paced market.

"Humour in advertising is like a gun in the hands of a child. You have to know how to use it. Otherwise it can blow up on you".

In the case of television it can be referred to as commercials as well as advertisement. A television advertisement or television commercial is a span of television programming produced and paid for by an organisation that conveys a message.

Advertisement revenue provides a significant portion of the funding for most privately owned television networks. People pay more attention to humourous advertisements than serious or factual one. Advertisers use humour as a tool to sell their products. The effective humour in advertisement grabs the attention of the audience towards the message and can make the advertisement more likeable. Conversely weak humour in advertisement can undermine its credibility. In total it can work for you or it can work against you. To make humour a successful tool, it is necessary to examine it.

Humour must be wisely used according to the products. Spotts et al. [1] used colour matrix approach to group products. Based on this the author found that the yellow coloured goods called "little treats" are suitable for the humorous advertisements. The Humour doesn't work for expensive and durable products (i.e.) products which are high feeling-oriented like Television, Refrigerator, Car, jewellery. Conversely it makes wonder when used for non-durable products (i.e.) products of low-feeling like snacks, gum, soft drinks and so on.

After deciding the product the advertiser must consider the target audience. Perception of humour differs from person to person, culture to culture and gender to gender. Men are likely to enjoy aggressive type of humour, while women are attracted to nonsensical humour. The person who finds something humorous might hurts some one's feelings. So the advertisers must be very careful in choosing the type of humour appeal. The researchers, like Tom et al. [2] have classified the types of humour as Comparison, Personification, Exaggeration, Pun, Sarcasm, Silliness, Surprise .This is the latest classification of humour appeals made by the researchers.

Humour must be related to the product, appealing to the target and must convey the message. When all the above mentioned factors are integrated in a humorous advertisement then it will attract the desired audience and will increase their liking towards that particular product.

If the humour in the advertising is so strong then it tends the audience to recall the advertisement. Advertising humour has relatively short life. The first time we see the ad we might enjoy it very much but when it becomes the repetitive process the audience gets bored. Old jokes die along with their product. So advertisers must keep on renewing their humorous concept and must keep it interesting. Humour does not improve or affect the buying nature of the audience.

Attention is enhanced if the type of humour is directly related to the product that is being promoted, therefore increasing advertising effectiveness will lead to attention enhancement. Audience do not prefer intentional humour (i.e), sarcasm. Relating the humour to the human experience will have a good impact on audience. This can also be called as slice of life. Humour should be the central to the product message. Commercials that have humour at the expense of others will be a great flop. People with more cognitive need gives importance only to the content or information provided in a commercial. They won't be affected by humour. People who look for humour in a commercial are not affected by the information provided in the commercial.

Almost all beverage and snack commercials uses humour as an appeal to promote their product. Humour attracts all the youngsters but it is less credible. So humour is not used for goods like jewellery and other expensive goods.

Despite the popularity of some humorous commercials, many consider them to be an annoyance for a number of reasons. The main reason is too much of exaggeration in them than the rest commercials. The increasing number of commercials, as well as overplaying of the same advertisement is secondary annoyance factors. Repetition helps in recall factor but over repetition of commercials might turn into a great menace. The humorous commercials to be successful must first grab the attention of the audience; the commercial must further create

*Corresponding author: Shobana Sankaran, Masters in Electronic Media, CEG, Anna University, Tamil Nadu, India, E-mail: letterbox.1490@yahoo.co.in

Received April 28, 2013; Accepted August 12, 2013; Published August 20, 2013

Citation: Sankaran S (2013) A Study on the Food Product Commercials in Television with Reference to Humour Appeal. J Mass Communicat Journalism 3: 158. doi:10.4172/2165-7912.1000158

Copyright: (C 2013 Sankaran S. This is an open-access article distributed under the terms of the Creative Commons Attribution License, which permits unrestricted use, distribution, and reproduction in any medium, provided the original author and source are credited. 
interest to sustain the audience. In the next stage the commercial must create a situation for the customer to enjoy the benefits of the product (i.e.) the user in of the product in the commercial can be shown delighted or contented after using the product. Then the audience must be motivated by using offers. Beyond all this the buyer should feel satisfied after using the product. This parameter helps to make the customer brand loyal in long run.

Advertisers find it easy to create memorable advertisement than it is to create an advertisement that makes the product memorable. People often remember the commercial but not the product. This problem is called, "Vampire Creativity". The selling story of the advertisement can be so mesmerizing that it obscures the product quality. Using humour and celebrity can cause this problem [3]. Humorous commercials it arouses feeling and entertains, helps to attract attention and it makes people laugh.

There is no specific Indian study on how different humour appeals are used in food based commercials. Many studies have proven that humour helps in ad recall.

Visual humour has more effect than the dialogue oriented humourous commercials. The visuals can easily cross the language barrier where as dialogue oriented humours dies within the particular region.

When the usage of violence and humour interface in television commercials were researched it was found that comedy shows contained more violence when compared to other types of shows. Based on their results the authors conclude that humour is not being used to reduce aggression in viewers but they trivialize violence which is likely to be imitated.

Relief theory conveys that people laugh because they need to reduce their physiological tension from time to time. So when people happen to watch a humorous commercial they enjoy the commercial and that helps them to release their stress, thus making them to relax. The following research is a study on the food products commercial in television commercial with humour appeal.

\section{Aim}

- To study the humour appeal present in Food product commercials in Television.

\section{Objective}

- To analyze the elements present in food product commercials based on humour appeal.

- To determine the end user's perception of humour based food product commercials.

- To determine the recall factor in humour based food product commercials.

\section{Scope of the study}

Identifying the success ratio by using humour in food and beverage based commercials that can be generally used in advertising research. This study will help industries, advertiser and ad makers to know whether using humour in the television commercials really influences the consumer to buy a product

\section{Need for the study}

To explore the types of humour appeal, which is used as a tool in television commercials and getting a deeper understanding of it? Humour may also be misleading can be brought out only from the study.

\section{Literature Review}

A literature review discusses published information in a particular subject area, and sometimes information in a particular subject area within a certain time period. Many articles, books and journals have been referred for this topic. Most of the articles and journals dealt directly with the topic. References helped much in gathering ideas, information regarding the topic. The suggestions of the various experts helped the researcher to persuade the topic to the further step. The researcher enclosed short description of various references that she used for the research.In this section studies concerning different types of humour will be reviewed.

\section{Humour in advertisement}

'If you can make someone laugh, there is an emotional connection with them. And anything you say beyond that is going to be more meaningful."

As cited by Paul Washer one can sense the power of humour. It is not that easy to stir consumers emotions through regular or routine advertisements. The advertisers who realised this started using humour as a tool in their advertisements to sell their products to a large group of consumers

\section{Types of humour in advertising}

Humour has different appeals. Catanescu and Tom conducted a research in the year 2001. The study shows that varied types of humour appeals must be used in different types of media to create an effective impact among the audience. The researchers like Speck, have classified humour based on the following categories.

- Conceptual

- Theoretically oriented

- Technique-oriented or practitioner oriented

Catanescu and Tom used Reick's "Practioner-Oriented Classification System to establish the different types of humour. The practioner-oriented system included five types of humour as follows:

1) Exaggeration

2) Pun

3) Sarcasm

4) Silliness

5) Surprise

In order to give a completion the authors added two more categories to the Reick's "Practioner-Oriented Classification System (1997).

- Comparison

- Personification

These terms are defined as follows

Comparison: Putting two or more elements together to produce a humourous situation.

Personification: Attributes human characteristics to animals, plants and objects. 
Exaggeration: Overstating and magnifying something out of proportion.

Pun: Using elements of language to create new meanings, which result in humour.

Sarcasm: According to Reick, sarcastic comments or situations are classified as silliness. The authors included Sarcasm as a separate category.

Silliness: It ranges from making funny faces to ludicrous situations.

Surprise: Includes all advertisements where humour arises from unexpected situations.

The study suggests that different types of humours suits varied products. Their findings support the belief that humour is widely used and noticed to be a dominant feature in television advertisements. Among all the humour appeals, silliness is primarily used in television advertisements.

According to Weinberger and Gulas [4], the humourous advertisements falls under one of the following typologies. The typologies are as follows

1. Pun-Using elements of language to create new meanings which result in humour

2. Satire-The use of ridicule, sarcasm to expose and discredit vice.

3. Understatement-To represent in a weak or restrained way that is not borne out by the facts

4. Joke-Provokes laughter or cause amusement as a witticism

5. Irony-The use of words to express something other than and especially the opposite of the literal meaning.

6. Ludicrous-To cause laughter because of absurdity, incongruity and exaggeration.

7. Humorous intent-To create light hearted laughter and amusement.

\section{The effect of humour on memory: constrained by the pun}

Summer felt et al. found that pun is one of the categories of humour appeals. In the year 2010 they conducted a study to measure the effect of humour on memory that is constrained by the pun. They even had a series of experiments to investigate the effect of pun humour on memory. In the experiments the participants were continuously exposed to non-stop jokes in two forms, where one form retained the pun and the other without pun. The results that was noticed at the end of their experiment proved that:

$>$ The pun humour improved both recall and recognition memory.

Rehearsal is not the cause of the humour effect on memory.

The constraints imposed by puns may account for the humour effects observed.

Puns constrain and limit the information that can fit in the final line of a joke and thus make recall easier.

\section{The role of intentional humour}

"Humour in advertising is like a gun in the hands of a child. You have to know how to use it. Otherwise, it can blow up on you." Cited by Miller.
In the year 2008, Beard underwent a study on the role of intentional humour in advertising and offense it created on audience. The study supported the earlier research works and found that, there are three humour mechanisms or process -Incongruity resolution, Arousal safety, Humourous disparagement. When these three processes are used individually or brought together, it generates five humourous types of advertisement [5].

Incongruity based: The incongruity humour is perceived at the moment of realization of incongruity between a concept involved in a certain situation and the real objects thought to be in some relation to the concept. It heightened emotional content of any kind with or without resolution.

Arousal Safety based: The arousal-safety humour provides an escape or relief from a form of constraint. This escape, or relief, may either be from social norms set by society. Any joke or pun that requires minimal effort by the viewer to solve.

Disparagement based: This is based on hostility, superiority, malice, aggression, derision, or disparagement within a social or interpersonal context All advertisements that used disparagement with or without Incongruity/Arousal safety and any display of an effort to derive humour from disparagement contexts.

Beard's [5] review of the advertising humour literature led him to suggest that arousal-safety humour might frequently lead to offense compared to the other humour types.

The findings of the study conducted by Beard confirm that intentional humour present in advertisements is what audience members complain about.

The findings also suggest that audiences are more offended by inherently offensive themes than anything else and when an intentionally humourous advertisement offends, it is likely because it is a certain type of humour that frequently includes an inherently offensive theme.

\section{Types of comedy}

Stern [6] divides comedy into four types based on Henri's theory of laughter. Henri states that, "Laughter is a sort of social gesture that aims at improvement". The four types of comedy are as follows

Physical comedy: According to the author the comedy is physical when the action is emphasised. The physical comedy occurs when the character's inflexibility is illustrated. Physical comedy in advertising is best actualized on television for gags and tricks.

Verbal comedy: In verbal comedy language is the key element. It emphasizes speaking. In this case the language itself becomes comic. George Meridith, a German novelist and critic repeatedly refers to verbal comedy as, "Comic Intelligence", pointing out that the spirit of verbal comedy, "laughs through the mind, for the mind directs it"[6].

Romantic comedy: Playfulness is one of the aspects of romantic comedy. This type of comedy is used for presenting solution to life ills. They are ideally suited for advertising. The advertisements which emphasizes on ritual, novelty and communion fall under this category.

Satiric comedy: It expresses individual or collective imperfection which calls for an immediate corrective. The author explains that just as the romantic comedy seeks to persuade by pleasant characters so does satiric comedy seeks to persuade the audience by ridiculous characters. 


\section{Impact of humour on advertising effectiveness}

In the year 1997, Spotts et al. [1] identified five types of humour based on the combination of the former mentioned three humour mechanisms. They are as follows,

1) Comic Wit

2) Sentimental Humour

3) Satire

4) Sentimental Wit

5) Full Comedy

They identified that the humour is mostly related to the message or the product using the given characteristics,

Humour dominant: Product messages are presented within a humourous context that shapes the over all experience of the ad. If the humour is removed the ad does not make sense.

Information focused: Humour in advertisement is semantic and message, arguments and require a different processing style than that in humour dominant advertisements. If humour is removed, the ad still makes sense.

Image focused: Humour in the advertisement is visual and closely related to the product and user. If the humour is removed the advertisement still makes sense.

\section{Humour in advertising-impact on recall factor and social setting}

As Lowther says, "Advertising is there to create a positive reaction to the brand, and the most tangibly positive reaction is laughter", the humour in an advertisement creates an impact on the brand image.

In the year 1991, Zhang and Zinkhan have made a study about the impact of humour on advertising. They studied the impact on the specified three factors.

- Perceived humour

- Attitude towards the brand

- Ad- recall

Their research findings suggest that humour increases ad information recall and also positively affects the brand attitude. This research findings are totally differs from Belch [7] who found humour did not affect the recall factor.

The researchers conclude that humourous ads have persuasive power than the serious ads. The repetition of these humourous ads aid in ad-recall.

Sutherland [8] claims that humorous advertisements attract audience but the message is not recalled and not considered credible. The serious advertisements are likely to be more credible and more have more authority.

\section{Impacts of humour in advertisements}

Earlier studies supported that humour has both negative and positive impacts. In the year 1993, Stephen underwent a study to find whether the humour enhances the systematic process of an advertisement. The author ended up with a negative result. He found that humour disrupted the systematic processing. The audience exposed to humorous advertisements were uninfluenced by the ad claim. Yilin's findings are contrary to the former author. The author said that humour in advertisements indirectly plays positive roles in image shaping. The humour helped to create some happy, funny and thus positive moods in the advertisements Humour in advertisements grabs people's attention and making the advertisement memorable. It lets the people like the advertisements.

\section{Humour and product type}

The product type is one of the important factors that has a significant influence on the effectiveness of humour in advertising. The products which seem to be best suited for humourous advertisements are non-durable, day to day rewards such as snack food, desserts, beer, alcohol and tobacco [9]. Spotts et al. [1] used the product colour matrix approach to group products to understand the effects of humour. The colours are white, red, blue and yellow.

White products: The white products have high risk that is often but not always based on price. These kinds of products full fill functional needs. Examples of white goods are refrigerators, washer/dryers and other such appliances. They are durable and expensive due to their functionality. Products like automobiles and insurance also come under this category.

Red products: The red colour represents extravagance and expressive. Conspicuous products that represent the individual. Both the red and white goods have high risk. The difference between them is the white goods satisfy a functional goal and red goods help to satisfy self- expression goals [1]

Blue products: The blue colour represents the low- risk and routine products. Example for blue products are tooth paste, toilet soap, detergent, mouth wash. These products help to accomplish small and routine tasks.

Yellow products: The yellow colour represents day- to-day rewards. The products like snacks, chips, candy, soft drinks, gum, beer and cigarettes are yellow products. They are less expensive and regularly purchased products. They fall under low risk. They are similar to red a goods which satisfies wants and are expressive but yellow products are not that important. Spotts et al. [1] examined the effectiveness of humour in these products. The authors found that the humour lowered the performance of both red and blue product advertisements. The humour had no impact in white goods advertisements. Only the yellow goods had positive impact due to the humorous advertisements. Weinberger and Spotts [4] had made a similar study and that showed similar results. The results were the higher risk red and white products have the lowest levels of humour usage with lower risk yellow and blue products the highest. The yellow goods had a positive impact due to humourous advertisements.

\section{Humour and persuvasiveness}

Sternthal and Craig [6] concluded that the distraction effect leads to persuasion. When compared to serious appeals, humour appeals are more effective and persuasive. Madden and Weinberger [10] found that only $26 \%$ practitioners agreed with the statement that proclaimed humour is more persuasive than non-humour. Inspite of this most of the U.S advertising executives agreed to the former statement of Sternthal and Craig.

Speck found that three out of two five humour treatments increased the persuasion of the humour. Similarly Brooker [11] found that humour appeal is more persuasive than the fear appeal. Mccollum et al. 
Citation: Sankaran S (2013) A Study on the Food Product Commercials in Television with Reference to Humour Appeal. J Mass Communicat Journalism 3: 158. doi:10.4172/2165-7912.1000158

[12] found that there is no effect of humour on persuasion. In contrary to the above findings Lammers et al. [13] and Basu et al. [14] founded that a humour has a moderate amount of persuasiveness. Weinberger and Campbell (1991) found that humour was more persuasive for lowinvolvement feeling products (yellow goods) than high-involvement feeling products.

\section{Humour and the target audience}

Most of the researchers claim that humourous advertisements are best suited to target better educated younger males (Madden and Weinberger 1984). In a review of literature claimed that men are likely to enjoy aggressive and sexual humour more than women and where as women appear to enjoy nonsensical humour. These results are not conclusive as the mind set and the society changes in a period of time. A fundamental problem in developing innovative message lies in the use of the same advertisement for an audience of great diversity [15].

Davis found that the effect of humour doesn't differ upon gender. In addition to gender there are many other factors like culture, age that may impact the effectiveness of humour. Humour is a universal human process exhibited by people of all cultures and throughout all of recorded history [16]

Cultural backgrounds are one of the most important factors that has to be considered. Humour in advertising cross-culturally indicates differential use of humour among countries, both in humour types employed and in absolute levels of humour used [16, 4]. Humour in advertisement is a major facilitator factor in communication. The use of humour in advertising is susceptible to two major drawbacks: Firstly the target audience may not be able to understand the humour used in advertisement. Secondly the audience may just stop at the humorous element and may not take interest in the message and the substantive advertising content [15].

These findings imply that inspite of the language barrier the humour is not translatable among different cultures. Humour differs according to the culture and country. Some may perceive it as humour and some who are conservative may get hurt.

\section{Incongruity humour}

According to Mooji, incongruity is one type of humour that works across all the countries. The incongruity is based on a contrast between the partly or fully contrasting scripts. There are two related humour types, incongruity and incongruity resolution. When both are used together in an advertisement it allows for maximum message variation. The theorists believe that incongruity combined with resolution enhances the unexpected situation and creates a greater humour impact. These incongruity resolution theorists suggest that a humorous response depends on

1. Rapid resolution of the incongruity.

2. A "playful" context with cues signifying that the information is not to be taken seriously.

3. An appropriate mood for the listener.

Stern [6] claimed that incongruity theory does not allow for the socially constructed nature as an interaction between a giver and the receiver of the humour. It considered humour as an individual rather than as a social phenomenon.

\section{Humour a tool for seeking audience attention}

The researchers believe that the humorous advertisements gain more attention from the audience when compared to nonhumorous advertisements [10]. The studies conducted on actual magazine advertisements [10], television advertisements, and radio advertisements [4] in standard industry advertisement testing situations humour has been found to have a positive effect on attention. Humour can aid in persuasion of the audience [17].

Speck compared humourous advertisements with non-humorous on four attention measures as follows

5. Initial attention

6. Sustained attention

7. Projected attention

8. Overall attention

The author found that humorous advertisements measured more than the non-humorous advertisements in each attention measures. Also the researchers examined the attention attracting ability of humour and ended up with the positive results.

\section{Serious side of humour}

Humour must be used to appropriate product or else it will result in failure. To make this clear and easy, Petty and Cacioppo [18] came up with Elaboration Likelihood model (ELM) (Figure 1).

The ELM model has two types of routes as follows

- The Central route: It is reflective and requires mental effect. Relies on cognitive elaboration, thinking about reflecting on a message.

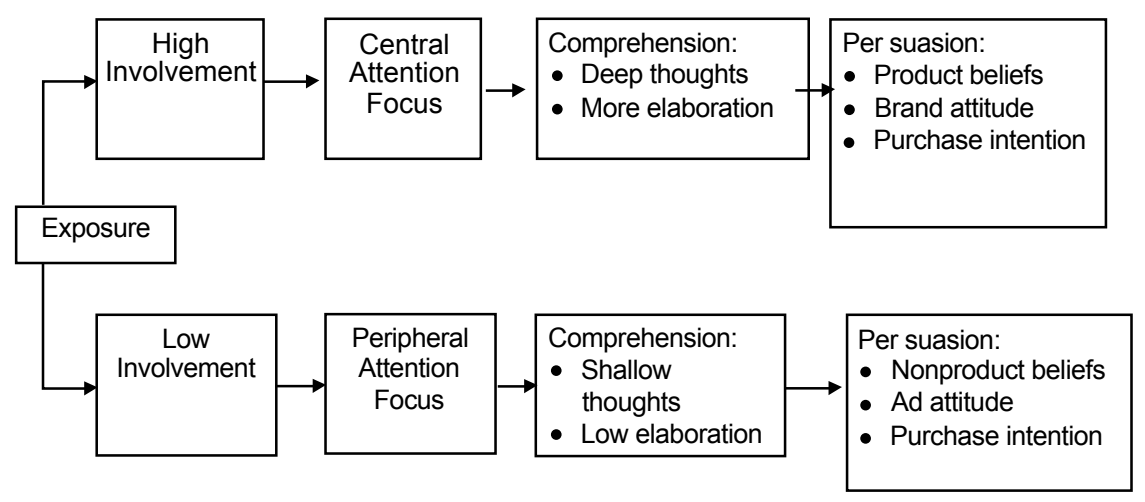

Figure 1: The ELM model has two types of routes as follows. 
Say for example if a person is car shopping, he/she looks upon the informations like long mileage, good reliability and performance and decides to buy the car. This is because the person found the information very convincing. He/she has the,

o Motivation (willingness) to process a message

o Ability to process (understand) a message

- The Peripheral route: The peripheral route to persuasion involves being persuaded in a manner that is not based on the arguments or the message content. For example, Experts can be trusted, "As seen on TV",

o ource attractiveness (celebrity endorsements) "Dhony is in the advertisement, so it has to be good."

o Perceived similarity: "I'll study with her, she also likes science."

Role of involvement: High involvement increases the likelihood of central processing, e.g. message scrutiny

Low involvement increases the likelihood of peripheral processing.

High involvement decreases reliance on credibility.

The elaboration likelihood model reminds us that humour is more effective with low-involvement decisions than with high-involvement ones. Therefore consumers who process information along the central route will not be persuaded by humour but rather by the argument strength of the advertisement. Conversely humour can be when it is processed along the peripheral route. As per the ELM studies, the peripheral route is utilized when the personal relevance is low. Thus humour can be used as an effective peripheral cue in the persuasion process. Zhang [19] examined the person's need for cognition and the use of humour. The author concluded that there was a relation between the need for cognition and the effectiveness of humour in advertisements. Humour does not work for people with high cognition need as they aim and look upon the message content. Conversely people with low cognition need are easily persuaded by humour. These conclusions were based on ELM.

\section{Violence in humor}

In the year 1998, Potter and Warren investigated humour and violence interface in the context of television. The authors found that comedy shows contained more violence when compared to other types of shows. Based on their results the authors conclude that humour is not being used to reduce aggression in viewers but they trivialize violence which is likely to be imitated. Specifically considered the combinations of humour and violence in advertising. After experimenting they found that $87.7 \%$ of the violent commercials included humour. Potter claimed that violence is acceptable if presented in a humorous context. Based on incongruity theory the combination of violence and humour creates an unexpected scenario which attracts the audiences. This could also be an unfortunate outcome if the viewers actually find violence more acceptable and likable when portrayed in humorous tones.

\section{Visual verses word play humour}

Vidler, an European creative director of Still Price Lintas, says: "If a funny ad is going to travel, it has to be visual, because otherwise you get into the idiosyncrasies of what makes different nationalities laugh. Most people share the same visual sense of humour."

In the year 1994, Archer and Belinda underwent a study whether humour cross borders (i.e. world wide). They found that humour must focus on visuals, must avoid language based puns, and avoid open national references. Many nations don't consider humour as an advertising tool especially countries like France, Italy etc;

\section{Theories of humour}

Pondered for theoretical understanding of humour in advertisements. Later three theories emerged. They are as follows

Relief theory: The two prominent relief theorists are Herbert and Sigmund. The theory describes humour along the lines of tensionrelease model. It discusses essential structures and psychological process that produce laughter. The two version of relief theory

I. The strong version: It holds that all laughter results from a release of excessive energy.

II. The weak version: It claims that it is often the case that humorous laughter involves a release of tension or energy.

Thus relief theory conveys that people laugh because they need to reduce their physiological tension from time to time.

Superiority theory: Superiority theory states that people laugh because they feel triumph over others. The two forms to the claims of the superiority theory of humour are

I. The strong claim: It holds that all humour involves a feeling of superiority.

II. he weak claim: It suggests that feelings of superiority are frequently found in many cases of humour.

Incongruity theory: It states that people laugh at things that are unexpected or surprising [4].

The modern humour theorists believes that humour can be explained by more than one theory.

\section{Humour and comprehension}

The studies conducted to determine humour and comprehension have shown great difference. In the literature review by [6] found humour has negative effect on comprehension. Furse conducted a study using 1000 television commercials and found that humour in commercials have explicitly increased the comprehension. Humour has the power to have an effect on information processing for making purchase decision by attracting attention, creating pleasant mood. It also influences consumer's attitude towards the brand [3].

In total seventeen studies have been conducted examining this relationship between humour and comprehension. Six of these studies claimed that a positive relationship existed between humour and comprehension, while six suggested a negative relationship and five showed neutral results [20]. Humour is easy to spot and enjoy, often triggering instantaneous laughter. At the same time it is hard to analyze and may evaporate on analysis [17]. Speck in the year 1987 conducted a research to find the relationship between humour type and comprehension. The author found that comic wit had a negative effect on comprehension while the other humour types (satire, full comedy) had positive effects on comprehension. Humour alone won't make a commercial successful. The unique selling proposition must be there in the commercial, "Buy this product and you will get this benefit" [21].

\section{Factors that influence humour}

There are numerous factors that influence the effectiveness of humour in advertisements. Madden et al. [10] research determined 
that humour is most effective when it relates to the product. In the year 1991, Speck empirically concluded that advertising messages that do not explicitly relate to the topic may be harmful to the advertising effectiveness.

Tyson said that marketers must thoroughly understand the target market or target audience of their product when using humour. The research by Gulas and Weinberger [4] concluded that use of humour is more successful with existing products rather than new products. Madden [10] found that humour has more effect in television medium. According to Solomon [22] if the consumer likes the advertisement then it means the message is delivered to the consumer in the desired way. The advertiser displays the product according to the user's needs and wants [23]. The consumer behaviour sustains due to the culture, when the culture, traditions, trends and custom changes then the users choices will change. The humour used in durable goods such as clothing, jewellery etc will result in worst output where as it gives a positive result when used in non-durable goods such as snacks etc [9]. Humour used for advertising the real products are effective while the humour used for the fictional products are ineffective [20]. To make a successful humorous advertisement we must the difference between the joke and humour. Joke is one shot deal which doesn't have the same funny effect when the audience hear it for the second time while humour by contrast makes the audience to see and hear it repeatedly. "Have fun with your product but don't make fun of it" [24]. Successful television commercials tend to fall into the following types, they are Problem solving, Comedy, Slice of life, Testimonials, Talking heads, Characters, Demonstrations. Humour can be combined with these types and hence it will be a successful commercial [25]. The fictional products are adopted and made from famous cartoons or after some fantasy movies. Say for example after the famous cartoon Simpson and his family many products that were used and showed in the cartoon were produced in real life. Few like Cheesy proofs (simpsons), Harry potter candies etc. The real products are not imitated from any fiction. So while using humour the advertiser must consider the product type.

Most researchers [19] agree that general benefits of humour include

- Increasing the audience attention

- Creating positive emotions

- Enhancing overall attitude toward the advertisement while its ability to increase its comprehension is limited.

Integrating all these factors and considering ELM, which states that low-involvement and feeling oriented products best suited for humour, the humour can result in a successful outcome.

\section{Implication of the review}

The main part was about the categorization of humour appeals. The researcher will rely on study which explained seven different kinds of humour appeals. Spotts et al. [1] used colour matrix approach to group products. The following research will be based on Yellow goods-Food products which are routine needs and in which the effect of humour will be more. Humour aids in recall factor and attracts attention. Humour is more effective for low-involvement and low feeling oriented products and also for yellow goods. The humour content must be prepared accordingly to the target audience as it is one of the effectiveness deciding factors. Humour persuades the audience to buy the product, when it is used for the according product. Most of the researchers have studied and examined about the humour as such but only few has targeted the types of humour.

\section{Theoretical Framework and Methodology}

\section{Introduction}

Research methodology is a collective term for the structured process of conducting research. Research methodologies can be quantitative and qualitative.

\section{Research design}

Designing of the research is done mainly to solve the problem of getting the various stages of the research under control. With the help of the research design, one can very easily handle and operate research work. The researcher of this study has adapted the following methodologies.

\section{- Content analysis}

- Survey

- Expert interview

Content analysis: A content analysis is a research tool used to analyze a topic by interpreting words and images from documents, newspaper, commercials, film and so on. The content analysis is of two types one is "Conceptual" and the other is "Relational content analysis". The researcher of this study has opted conceptual content analysis.

\section{Conceptual content analysis}

Conceptual analysis is a technique that treats concepts as classes of objects, events, properties, or relationships. The technique involves precisely defining the meaning of a given concept by identifying and specifying the conditions under which any phenomenon is (or could be) classified under the concept in question. Fourteen food based humorous Indian television commercials of the years 2012-2013 were taken and analysed. Content analysis was done based in the following parameters Visuals, dialogues, Music, Characterization, Ambience, Appearance of kids, unusual sound effect, brand image appearance, Tagline, Location, Animation, Humour appeal, target audience.

Sampling: A sample is a group of people, objects, or items that are taken from a larger population for measurement. The sample should be representative of the population to ensure that we can generalise the findings from the research sample to the population as a whole. The researcher has chosen random sampling with age group of 20-40. The samples were around 200. The questionnaire was distributed online and in person. There were around sixteen questions among which many are multiple choice questions. The survey helped the researcher to find about the impact of different types of humour appeals in food based commercials. Also the researcher was able to find the highly used appeal.

Expert interview: In this method the researcher interviews the person who is an expert in the particular field of research and gets views on the research topic. The content writers of advertising agencies were chosen and they gave their opinion on humour content in food based commercials. The media experts also gave their opinion on using humour appeal in food based commercials.

\section{Theoretical Frame work}

Relief theory: The two prominent relief theorists are Herbert and Sigmund. The theory describes humour along the lines of tensionrelease model. It discusses essential structures and psychological process that produce laughter. The two version of relief theory. 
Citation: Sankaran S (2013) A Study on the Food Product Commercials in Television with Reference to Humour Appeal. J Mass Communicat Journalism 3: 158. doi:10.4172/2165-7912.1000158

Page 8 of 9

III. The strong version: It holds that all laughter results from a release of excessive energy.

IV. The weak version: It claims that it is often the case that humorous laughter involves a release of tension or energy.

Thus relief theory conveys that people laugh because they need to reduce their physiological tension from time to time.

Superiority theory: Superiority theory states that people laugh because they feel triumph over others (Meyer 2000). The two forms to the claims of the superiority theory of humour are

III. The strong claim: It holds that all humour involves a feeling of superiority.

IV. The weak claim: It suggests that feelings of superiority are frequently found in many cases of humour.

Superiority theory relates to the sarcasm appeal in humourous commercials.

Incongruity theory: It states that people laugh at things that are unexpected or surprising.

This theory proves that audience prefer surprise humour in commercials.

\section{Method}

\section{Content analysis}

The most viewed fourteen humorous food product commercials were chosen and were analyzed. The commercials are Bingo tangles, Kit kat, Center fruit, Center fresh, Snickers, Dairy Milk, Big babol Fillyfolly, Gems, Kopiko, Sprite, Perk, Oreo, Alphenlibe Juzt Jelly and Chingles. The interpretations of the content analysis are as follows.

Exaggeration and silliness are the most used appeals. Next to Exaggeration and Silliness, Sarcasm is used more. Personification and Surprise are the least used appeals. Pun is not used in humorous food based commercials. Exaggeration/silliness/sarcasm/surprise are clubbed together and used in most of the commercials.

Characterization: 7 out of 14 commercials were characterized as professional characters, 4 out of 14 were family basedand the rest three were strangers. The major characterizations are professional based.

Visuals/Dialogue: Among the 14 commercials 8 commercials were visual based and the 6 were dialogue based. Visual commercials lead the dialogue based commercials

Use of music: Out of 14 commercials, 9 had background music, 4 had songs and the music was not used in the remaining single commercial.Music is used majorly than the song.

Visual tagline: 11 out of 14 commercials used visual Tagline. Usages of funny taglines are more.

Surrealistic/Real visuals: Among 14 commercials 7 had real visuals and the rest 7 had surrealistic visuals. Both the surrealistic and real visuals are used equally in the commercials.

Ambience/location: Out of 14 commercials 4 were shot outdoor, 3 were shot both indoor and outdoor and the remaining 7 were shot indoor. Indoor ambience is mostly preferred in the commercials

Animation: Among 14 commercials, animation is used in 6 commercials. Animation is used as a part of real characters. Specific animated character is not used.

Unusual sound effects: Among 14 commercials, out of place, unusual or bizarre use of sound is used in 5 commercials. Unusual Sound Effects are rarely used.

Brand name: Out of the 14 products, 4 products are Cadbury brand, 5 are Prefetti brand. The rest all are different brands. Cadbury manufactures are highly using humour appeal for their products next to Prefetti.

\section{Survey}

Participants: The participants of age limit 20-40 were selected. The sample size is 200. General audience were circulated with a questionnaire of 16 questions.

\section{Results}

Exaggeration and sarcasm are the most used humour appeal in food product commercials. $72 \%$ of the people don't enjoy sarcasm. $84 \%$ of the people feel that there is a moderate use of exaggeration in food product television commercials. Humour content, Celebrity endorsement, Characterization, Dialogues, Music and Visuals help them to recall the commercial. Humour as an element helps the audience to recall the product name.

\section{References}

1. Spotts HE (1997) Assessing the Use and Impact of Humor on Advertising Effectiveness: A Contingency Approach. Journal of Advertising 26: 17-32.

2. Tom GC (2001) Types of humor in Television and Magazine Advertising Review of Business 22: 1.

3. Sharma RSS (2006) Advertising planning and Implementation. Prentice-Hall of India Private Limited.

4. Weinberger MG, Gulas CS (1992) The Impact of Humor in Advertising: A review. Journal of Advertising 21: 35-59.

5. Beard FK (2008) Advertising and Audience offense: The Role of Intentional humor. Journal of Marketing Communications 14: 1-17.

6. Sternthal BA (1973) Humor in Advertising. Journal of Marketing

7. Belch GE (1984) An Investigation of the Effects of Repetition on Cognitive and Affective Reactions T0 Humorous and Serious Television Commercials. Association for Consumer Research 11: 4-10.

8. Sutherland JC (1983) The Effect of Humor on Advertising Credibility and Recall of the Advertising Message. The American Academy of Advertising.

9. Campbell LP (1995) The Use of Humor in Different Advertising Media. Journal of Advertising Research.

10. Madden TA (1984) Humor in Advertising: A Practitioner View. Journal of Advertising Research.

11. Brooker G (1981) A Comparison of the Persuasive Effects of Mild Humor and Mild Fear Appeals. Journal of Advertising 10: 4.

12. McCollum S (1982) Focus on Funny. Topline.

13. Lammers HB (1983) Humor and Cognitive Responses to Advertising Stimuli: A Trace Consolidation Approach. Journal of Business Research 11: 173-185.

14. Basu KA (1990) Humor in Advertising: The Moderating Role of Prior Brand Evaluation. Journal of Marketing Research 27: 4

15. Mohan M (2010) Advertising Management Concepts and Cases. Tata McGraw Hill Education Private Limited.

16. Alden DL (1993) An Examination of Cognitive Factors Related to Humorousness in Television Advertising. Journal of Advertising 22: 2.

17. Tellis JG (2004) Effective Advertising. Sage Publications Inc. 
Citation: Sankaran S (2013) A Study on the Food Product Commercials in Television with Reference to Humour Appeal. J Mass Communicat Journalism 3: 158. doi:10.4172/2165-7912.1000158

Page 9 of 9

18. Cacioppo JT (1981) Social Psychological Procedures for Cognitive Response Assessment: The Thought-Listing Technique. New York: Guilford.

19. Zhang Y (1996) Responses to Advertising: The Moderating Effects of Need for Cognition. Journal of Advertising Spring 28: 2.

20. Charles S, Gulas MG (2006) Humor In Advertising: A Comprehensive Analysis. M.E sharpe

21. Chatterjea G (2005) Advertising Karma. Rupa.Co.
22. Solomon M (2004) Consumer Behavior: Buying, Having and, Being. Journal of Consumer Research.

23. Newell JM (2007) Desperately Seeking Opt-In: A Field Report from a StudentLed Mobile Marketing Initiative. International Journal of Mobile Marketing 2: 53.

24. Bonnie L, Drewniany AJ (2009) Creative Advertising. India Binding House.

25. Cury I (2005) Television Commercials-How to make them or How big is the boat? Focal Press, Elsevier Inc. 